\title{
VIDA DE REFUGIADO, VIDA DE ESTRANHO A experiência angolana no Rio de Janeiro
}

\section{REFUGEE LIFE, STRANGER'S LIFE The Angolan experience in Rio de Janeiro}

\author{
Márcia Regina dos Santos \\ Universidade Candido Mendes, Instituto Universitário de Pesquisas do Rio de Janeiro, Programa de Mestrado em \\ Sociologia Política - IUPERJ. Rua da Assembleia, 10, $7^{\circ}$ Andar, Sala 702, Centro, Rio de Janeiro - RJ, Brasil, CEP \\ 20011-901. Email: msantosmil@gmail.com

\section{Rogério Ferreira de Souza} \\ Universidade Candido Mendes, Instituto Universitário de Pesquisas do Rio de Janeiro, Programa de Mestrado em \\ Sociologia Política - IUPERJ. Rua da Assembleia, 10, $7^{\circ}$ Andar, Sala 702, Centro, Rio de Janeiro - RJ, Brasil, CEP \\ 20011-901. Email: rogeriosouza@iuperj.br
}

\begin{abstract}
Resumo: O presente artigo tem como objetivo geral perceber e analisar o papel da memória coletiva e social na reconstrução identitária e na ressocialização de angolanos em situação de refúgio na cidade do Rio de Janeiro. O artigo parte de seis entrevistas exploratórias realizadas com refugiados angolanos no ano de 2018. Nessas entrevistas exploratórias foi percebido como as lembranças, memórias e esquecimento enredam e articulam estratégias pessoais e coletivas para a manutenção de suas origens, tradições e costumes frente à situação de refugiado em outro país. O apego às memórias torna-se uma marca indelével em suas trajetórias como refugiados, assim como, também, instrumentos importantes na construção e manutenção das identidades angolanas em estado de refúgio.
\end{abstract}

Palavras-chave: migração, refugiados, memória, identidade.

\begin{abstract}
This article aims to understand and analyze the role of collective and social memory in the reconstruction of identity and resocialization of Angolans in a situation of refugee in Rio de Janeiro. The article is based on six exploratory interviews carried out with Angolan refugees, in 2018. In these exploratory interviews, remembrances, memories and forgetfulness intertwine and articulate personal and collective strategies to maintain their origins, traditions and customs in face of the refugee situation in another country. Clinging to memories becomes an indelible mark on their refugee trajectories, as well as an important instrument in the construction and maintenance of Angolan identities.
\end{abstract}

Keywords: migration, refugees, memory, identity.

\section{Introdução}

O cenário de deslocamento global de pessoas, sejam migrantes ou refugiados, tem sido modificado, na última década do século XXI, pelo acirramento das diversas crises internacionais existentes, que têm como causa numerosos e complexos fatores que vão de interesses da macroeconomia mundial a disputas étnicas e questões climáticas, para citar apenas alguns, e que pode ser ilustrado, por exemplo, pelo conflito na Síria 
(2011), pela guerra civil no Sudão do Sul (2013-2018) e pela crise econômica, política e social na Venezuela (2015). Além disso, esses deslocamentos de pessoas entre estados nacionais ocorrem ainda em um contexto em que soberanias nacionais ainda são importantes e são os estados nacionais que decidem que dos não cidadãos devem entrar e permanecer no país. Cabendo, no entanto, como signatários das Nações Unidas, seguirem as leis, acordos e convenções estabelecidas pelo Alto Comissariado das Nações Unidas para Refugiados-ACNUR (Goodwin-Gill, 2014).

Em seu relatório anual, Tendências Globais, publicado em junho de 2019, ACNUR/ UNHCR aponta que, "ao final de 2018, cerca de 70,8 milhões de pessoas foram forçadas a deixar seus locais de origem por diferentes tipos de conflitos. Desses, cerca de 25,9 milhões são refugiados e 3,5 milhões são solicitantes de reconhecimento da condição de refugiado" (citado em uma apresentação do Ministério da Justiça e Segurança Pública) ${ }^{1}$.

Este problema, no entanto, não é recente. Na década de 1990, o Brasil foi uma das rotas escolhidas para a migração forçada de milhares de angolanos em fuga da Guerra Civil em seu país. Até 2008, os angolanos ocuparam o primeiro lugar em número de solicitações de refúgio, entre outras 42 nacionalidades solicitantes (Cáritas Brasileira, 2007, 2008), e, em 2017, início de nossa pesquisa, o Brasil contava com a presença de 1.420 angolanos reconhecidos como refugiados, ficando atrás, apenas, dos sírios (2.298 reconhecidos). Particularmente, na cidade do Rio de Janeiro, entre 1990 e 2005, 2.286 angolanos foram reconhecidos como refugiados, representando $56,2 \%$ de todos os estrangeiros nesta categoria no município. (Cáritas Brasileira, 2007, 2008)

O último levantamento do ACNUR, já referido, do ano de 2019, indica que o Brasil tem, hoje, aproximadamente 1.011 angolanos na condição de refugiado, cerca de $9 \%$ do total refugiados no país, e 675 solicitações de refúgio por esses nacionais encontram-se em tramitação (citado em uma apresentação do Ministério da Justiça e Segurança Pública) ${ }^{2}$.

A migração se apresenta como um fenômeno social de dupla dimensão, na medida em que engloba dois eventos distintos, - emigração e imigração (Sayad, 1998), e aos quais correspondem problemáticas também distintas. Entretanto, o conceito de migração traz consigo subcategorias como refugiados, asilado político e migrante ilegal, que acabam se misturando e se banalizando em inúmeras situações e corroborando para inúmeros preconceitos e estereótipos simplistas. (Cierco, 2017). Cabe assim, para efeito de uma pequena definição conceitual para este artigo definir em poucas palavras cada uma dessas subcategorias.

Em geral migração internacional se diferencia de outros tipos de deslocamentos de pessoas como turismo e viagens para realização de negócios, pois não implicam em mudança de residência, redefinição das relações pessoais, reorganização 
das atividades vitais, e serem transitórias. A migração internacional em detrimento das questões tempo, espaço e sociabilidade está ligada a uma questão política, pois cabe ao estado nacional sancionar ou não a entrada e permanência do não cidadão em seu território.

Assim, para que as migrações internacionais aconteçam não é suficiente as disparidades de rendimento entre países, ou a vontade de sair e o desejo de entrar noutro país. É o exercício do direito de soberania de controlar quem pode entrar, permanecer e pertencer ao Estado-nação que define as migrações internacionais como um processo social específico. (Cierco, 2017, p. 12).

Assim sendo, o processo migratório além da questão da realocação física do sujeito há também questões pertinentes à jurisdição e de pertença. Destarte, o fenômeno da migração internacional tem envolvido inúmeras formas, facetas, motivações e enquadramentos legais, dentre elas as que mais se destacam são os de caráter laborais (trabalhadores legais e ilegais) e as migrações de refúgio e pessoas deslocadas (Cierco, 2017, p. 12). Este último sendo objeto de análise neste artigo.

Quanto a definição do conceito de refugiado, cabe antes de mais nada, destacar que inúmeros autores ${ }^{3}$ apontam para uma enorme confusão conceitual devido às inúmeras implicações políticas e sociais que o significado de refugiado, ao longo dos anos, foi sendo atribuído. Portanto, cabe destacar que um refugiado deixa o seu país de origem devido o iminente perigo de morte e perseguição política, ou seja, para fugir do estado de insegurança. Ele, o refugiado, tem que abandonar o seu país, seu domicílio, sua família migrando muitas das vezes para lugares onde não possui auxílio econômico e não domina a língua. Dito isso, tornar-se um refugiado representaria para o indivíduo uma grande sensação de perda, um trauma que incute sentimentos de dimensões sociais, psicológicas e jurídicas (Cierco, 2017, p. 13). Ou seja, sair do seu país a procura de refúgio representaria "o último ato de um longo período de incerteza, que surge só depois de terem falhado todas as outras estratégias de sobrevivência. (Cierco, 2017, p.13)

Segundo Teresa Cierco (2017), no âmbito do direito internacional, o conceito de refugiado é resultado da interpretação de três instrumentos internacionais, a saber:

(...) o Estatuto do Alto Comissariado das Nações Unidas para os Refugiados (ACNUR) de 14 de Dezembro de 1950, a Convenção de Genebra, de 28 de Julho de 1951, e o Protocolo de Nova Iorque, de 31 de Janeiro de 1967. De acordo com o artigo1 ${ }^{\circ}$ A (2) da Convenção de Genebra. [Assim] , o conceito de 'refugiado' aplica-se a qualquer pessoa: Que, em consequência de acontecimentos ocorridos antes de 1 de Janeiro de 1951, e receando com razão ser perseguida em virtude da sua raça, religião, 
nacionalidade, filiação em certo grupo social ou das suas opiniões políticas, se encontre fora do país de que tem a nacionalidade e não possa ou, em virtude daquele receio, não queira pedir a proteção daquele país; ou que, se não tiver nacionalidade e estiver fora do país no qual tinha a sua residência habitual após aqueles acontecimentos, não possa ou, em virtude do dito receio, a ele não queira voltar. (p. 14).

Ou seja, recebem atenção particular, dentro das categorias Refúgio, Asilo e Migração Forçada, todos aqueles considerados em situação de vulnerabilidade conforme critério estabelecido pelo ACNUR 4 .

Diante do exposto, este artigo, que tem origem em uma pesquisa de mestrado e se insere em uma pesquisa maior, realizada no âmbito do Laboratório de Estudo da Cidade e Cultura IUPERJ-UCAM ${ }^{5}$, na cidade do Rio de Janeiro, tem como foco a problemática da migração forçada e da condição de refugiado que lhe é conseqüente. Busca-se contemplar a narrativa dos angolanos e sua trajetória na cidade, como também, compreender e analisar o papel da memória na reconstrução identitária do sujeito na condição de refugiado.

O artigo traz, ainda, um conjunto de seis relatos que foram colhidos no ano de 2018, através de entrevistas exploratórias, com refugiados residentes na cidade do Rio de Janeiro. Optou-se por apresentar os entrevistados pelas iniciais de seus nomes, de modo a garantir maior liberdade aos depoimentos e de proteger, ainda que minimamente, suas identidades. Assim temos:

Tabela 1 Lista de entrevistas exploratórias com refugiados, residentes na cidade do Rio de Janeiro (RJ), 2018

\begin{tabular}{cccc}
\hline Entrevistado (A) & Sexo & Idade & Ano de chegada ao Brasil \\
\hline L.P. & M. & 45 & 1999 \\
P. & F. & 44 & 2002 \\
J.P. & M. & 35 & 2001 \\
E.G. & M. & 35 & 1992 \\
J.F. & M. & 38 & 1993 \\
A.M. & F. & 52 & 1995 \\
\hline
\end{tabular}

Foram empreendidas, também, conversas em instituições tais como: Consulado Geral de Angola; CEPRI - Centro de Estudos de Direito e Política de Imigração e Refúgio e Cáritas-RJ. Além disso, foi possível empreender uma observação participante em festas e atividades culturais realizadas pelos refugiados angolanos onde grande parte das entrevistas exploratórias foram realizadas. 


\section{Migração e Refúgio - Algumas abordagens e questões}

Frente à complexidade do fenômeno migratório, pesquisadores são estimulados a buscar compreensão, formular teorias e a propor alternativas de resolução para os problemas que ele produz.

Alguns dos atuais debates sobre migração evidenciam que ela coloca em cheque, hoje, a questão da nacionalidade e, sobretudo, do Estado-nação nos âmbitos da legitimidade desses conceitos, da validade da noção de fronteira e do problema da segurança. A esse respeito, Paola Gersztein afirma que:

(...) a nacionalidade é um construto social e jurídico que foi concebido para justificar a soberania de um determinado território e garantir a obediência de um povo, e se sustenta em um 'suposto vínculo entre pessoas', a partir da criação de elementos comuns - idioma, religião majoritária, p. ex., que possibilitam distinguir o 'nós, nacionais, que temos um elo com o Estado-nação', do eles. (Gersztein, 2017, p. 78).

Nesse sentido, junto com as questões de raça, classe e religião, a nacionalidade se apresenta como mais um elemento a nutrir o conjunto de problemas relacionados com a migração, na medida em que ela facilita a criação de rótulos, acentuando diferenças que são utilizadas como justificativa para toda sorte de discriminação e de recusa ao imigrante.

Zygmunt Bauman, analisando os efeitos da globalização na estrutura do Estado-nação e das sociedades, identificou um "crescente sucesso da xenofobia, do racismo e da variedade chauvinista de nacionalismo" (2017, p. 18) decorrentes dessa lógica, que prioriza o Estado e entende a permanência no país de nascimento como a norma e o deslocamento entre fronteiras como desvio.

Bauman assinala que ainda que elementos classistas, racistas ou religiosos estimulem opiniões e comportamentos contrários à imigração, também a população pertencente a essas minorias ou grupos sociais específicos se coloca como oposição aos imigrantes, pois a nacionalidade é o traço que iguala todos os nacionais. A nacionalidade “ (...) é uma característica que situa seus compatriotas na mesma categoria das pessoas boas, nobres, imaculadas, e poderosas situadas no topo, simultaneamente situando-os acima de estrangeiros também miseráveis" (2017, p. 19).

Também Póvoa-Neto (2012) identifica que existe uma crescente "criminalização" da migração, porém, em um sentido diferente daquela já conhecida, baseada na imigração ilegal ou irregular, como ocorre, por exemplo, nos EUA. Para ele, existe outro sentido presente no "anti-imigrantismo": 
(...) a sociedade, as forças políticas, os partidos políticos criminalizam o migrante não no sentido de prender, mas de lhe atribuir os problemas da sociedade. Quer dizer, o imigrante é apontado como responsável pelo desemprego, pela falta de segurança, pela sobrecarga dos serviços públicos. (...) no sentido de dizer que a insegurança nas ruas e os conflitos da sociedade ocorrem por causa deles. (...) essa visão criminalizante acaba virando uma ideologia anti-imigrantista. (Póvoa-Neto, 2012)

A compreensão, por parte do Estado e da sociedade sobre o que é, ou sobre como eles definem migração importa, porque é esse entendimento nacional sobre o evento que norteará normas e políticas institucionais do país para essa área, já que, é sabido que, não obstante a dificuldade de controle, os países sempre tentaram selecionar o tipo de imigrante que atravessa a sua fronteira, utilizando critérios que variam de interesses econômicos a diplomáticos. (Póvoa-Neto, 2012).

Claro está que a imigração contemporânea representa um problema para os Estados. Não a imigração do empreendedor, ou do turista, tampouco a da mão-de-obra barata. A imigração incômoda refere-se à dos indivíduos necessitados de asilo e de proteção que, do ponto de vista do Estado, significam um ônus orçamentário adicional, além de políticas específicas voltadas para pessoas que não constituem interesse econômico, nem social para os governos, consideradas, assim, como indesejáveis.

A obrigatoriedade de uma ação política de enfrentamento ao problema, em oposição à rejeição e à insatisfação em relação à questão engendrou o surgimento dos campos de atendimento humanitário para migrantes e refugiados ${ }^{6}$, um dos temas de investigação de Michel Agier. Para o autor (2006), a existência desses campos visa, antes, o controle de uma massa de indesejáveis, que impede uma aparência "limpa" e "saudável" de um país do que o efetivo atendimento e proteção a uma população fragilizada e desprovida de condições mínimas para sua dignidade e sobrevivência. "Com a constituição dos terrenos do humanitário como espaços de exceção, como não-lugares, a história política recente fez nascer uma categoria mundial de sem-lugar e sem-direitos mais ampla que a soma dos refugiados propriamente ditos." (Agier, 2006, p. 199).

Impeditivos de uma fachada clean para os Estados, os imigrantes forçados são um problema. Eis a distorção conveniente: reféns de uma situação que não criaram, impelidos, contra sua vontade, a deixarem tudo para trás em busca de amparo à sobrevivência, à mercê de favores de outros povos e nações, eles são o problema!

Essa percepção do imigrante como um enfado se difunde na sociedade e passa a sustentar lógicas, ideologias e comportamentos, como o anti-imigrantismo ao qual temos assistido pelo mundo. 


\section{Migração forçada angolana - Contexto histórico e identidade nacional}

A guerra pela independência da colonização portuguesa, que teve início em 1961, foi fruto de um nacionalismo produzido por diferentes elementos, alguns deles com maior relevância: i) a constante e crescente situação de humilhação, violência e desigualdade a que eram submetidos os africanos por parte dos colonizadores; ii) os movimentos de enfrentamento à ditadura salazarista em Portugal, um elemento exógeno, mas que contaminava o debate colonial em Angola; e iii) a ida de estudantes de diferentes países africanos para universidades europeias, o que proporcionou o debate e o intercâmbio de ideias (Moniz, 2018).

A partir dos debates e trocas começam a surgir, na década de 1950, em Angola e em Lisboa, diversos movimentos de emancipação e libertação nacional que se davam de maneira organizada e eram portadores da insatisfação de uma maioria que clamava pela descolonização, diante do acirramento do autoritarismo, da repressão política, das prisões arbitrárias e de toda sorte de maus tratos, que juntamente com a conquista da independência por outros países africanos aumentava o descontentamento, facilitando o recrutamento dos descontentes pelos movimentos.

É nesse cenário de insatisfação e nacionalismo que nascem, em Angola, os três movimentos - mais tarde, partidos políticos - protagonistas na luta pela independência: a Frente Nacional de Libertação de Angola (FNLA); o Movimento Popular de Libertação de Angola (MPLA) presidido por Agostinho Neto, personagem central nos episódios da descolonização e da Guerra Civil no país; e, a União Nacional para a Independência Total de Angola (UNITA), liderada por Jonas Savimbi, outro personagem central no conflito.

Esses grupos, embora movidos pelo mesmo objetivo naquele momento - a libertação de Angola da dominação portuguesa tinham origens étnicas e ideológicas diversas e, ao longo da jornada pela libertação, entre 1961 e 1975, as três legendas experimentaram uma recorrente dinâmica de aproximação e afastamento de interesses e de práticas, com muitos enfrentamentos diretos e violentos na disputa por territórios, por militantes e por apoiadores.

Após a independência, conquistada em 1975, esses partidos entraram em disputa pelo poder dando início à Guerra Civil Angolana, que durou 27 anos (de 1975 a 2002), dividiu o país e resultou em: " 2 milhões de mortos, 1,7 milhão de refugiados, milhares de órfãos, 200 pessoas mortas de fome por dia, 80 mil crianças, velhos, homens e mulheres mutilados pelas milhões de minas semeadas pelo país afora" (Marques, 2001).

O conflito contribuiu de forma drástica com o crescimento da mobilidade involuntária em diversos fluxos geográficos, que resultou na chegada do contingente 
de angolanos ao Brasil, em um processo que ocorreu em três etapas distintas: a primeira, entre 1975 e 1985, motivada por problemas consequentes da luta pela independência; a segunda, entre 1992 e 1994, no auge da Guerra Civil e, a terceira, a partir de 1998, após a quebra do acordo de cessar fogo, assinado em 1994.

A segunda dessas etapas produziu o grande contingente masculino de angolanos que veio para o Brasil fugindo da rusga - ação coercitiva utilizada pelo MPLA para recrutar jovens em idade para o serviço militar e obrigá-los a servir na guerra. Para proteger seus filhos da rusga, os pais providenciavam alteração da data de nascimento em suas certidões e, como a fuga da rusga colocava jovens e militares sob o status de desertores, antes de saírem de Angola, era preciso efetuar a troca de seus nomes para evitar interdição nos postos de emigração e perseguição no país de asilo.

Esse procedimento, de um lado, adiava o recrutamento e possibilitava a saída do país, entretanto, de outro, criava diversas dificuldades no país de asilo, caso de alguns dos entrevistados.

Literaturas sobre este tema (Pearce, 2017; Pinto, 2016) afirmam que a construção de uma nação e/ou de uma identidade nacional angolana esteve subordinada ao nacionalismo utilizado pelas elites políticas da Guerra Civil e, também, ao edificado, anteriormente, durante a elaboração dos movimentos de descolonização.

Assim, ao fim do conflito, havia no país a necessidade de construção de uma identidade nacional fundada em uma nova cultura angolana, fruto da soma e transformações de seus processos sociais e históricos, capaz de fundar uma verdadeira cultura angolana, como defendiam seus intelectuais, que refletisse os diferentes povos e matrizes culturais existentes no país.

Agostinho Neto expressa bem a percepção e o sentimento que subjaziam este projeto intelectual:

Os nativos são educados como se tivessem nascido e residissem na Europa. Antes de atingirem a idade em que são capazes de pensar sem esteio, não conhecem Angola. Olham sua terra de fora para dentro, e não ao invés, como seria óbvio. Estudam na escola, minuciosamente, a História e a geografia de Portugal, enquanto que as da Colónia apenas folheiam em sinopses ou estudam muito levemente. (...) Não compreendem essa gente que aqui havia os seus costumes e idiossincrasia. Não têm tradições. Não têm orgulho de sua terra porque nela nada encontram de que se orgulhar; porque não a conhecem. Não têm literatura, têm a alheia. Não têm arte sua. Não têm espírito. Não adoptam uma cultura, adaptam-se a uma cultura.

Os indivíduos assim formados têm a cabeça sobre vértebras estranhas, de modo que as ideias, as expirações do espírito são estranhas à terra. Daí o olhar-se esta, a sua gente e hábitos, o mundo que os rodeia, como estranhos a si - de fora. (citado em Pinto, 2016, p. 56). 
Stuart Hall sugere que as identidades parecem evocar uma gênese que habitaria um antecedente histórico e "com o qual elas continuariam a manter certa correspondência" (2000, p.107).

Elas têm a ver, entretanto, com a questão da utilização dos recursos da história, da linguagem e da cultura para a produção não daquilo que nós somos, mas daquilo no qual nos tornamos. Têm a ver não tanto com as questões 'quem nós somos' ou 'de onde nós viemos', mas muito mais com as questões 'quem nós podemos nos tornar', 'como nós temos sido representados' e 'como essa representação afeta a forma como nós podemos representar a nós próprios'. (2000, p. 109).

Assim, do prisma individual cada um dos angolanos tem autonomia - consciente ou não - para significar os eventos vividos, selecionar o que deve ser lembrado e o que deve ser esquecido da guerra, que acabarão por compor sua estrutura identitária.

Do ponto de vista da memória coletiva, no entanto, a guerra, enquanto evento histórico oficial, representa um marco de identidade nacional, um lugar de memória, mesmo que por ela perpassem ou possam caber, de forma implícita ou explicita, incontáveis memórias sobre o mesmo evento.

\section{Procedimentos e Estranhamentos}

No Brasil, as regras e procedimentos para a concessão de refúgio estão dispostas na Lei n ${ }^{\circ}$ 9.474/97 que, segundo especialista, demonstra intenção bastante humanitária, embora, profissionais da área jurídica considerem que ela é mal difundida apesar de seus 21 anos o que significa que "o procedimento de concessão de refúgio também o é" (Jubilut \& Gody, 2017, p. 9) O funcionamento dos mecanismos legais revela reflexos de uma burocracia rígida, gerenciada por e sob a discricionariedade de profissionais dos órgãos e setores responsáveis por atender à demanda dos numerosos solicitantes; os termos dispostos nos ordenamentos jurídicos dão margem a distorções e subjetividade; e os procedimentos de avaliação de cada situação também se sustentam em critérios técnicos difusos.

Ao nosso entender, expressões como grupo social, fundado temor de perseguição e, mesmo, violação de direitos humanos parecem determinar entendimento unívoco ou inequívoco. Porém, como definir exatamente um grupo social? Se subtraídas as categorias de entendimento mais habituais, como negros, mulheres e homossexuais, por exemplo, o termo torna-se bastante abrangente e difuso, e pode apresentar recortes variados em diferentes nações.

Outro exemplo que defendemos como difuso e variado é o caso de fundado temor de perseguição. Nele temos: fundado (que supõe um fundamento em questões 
objetivas) + temor (subjetivo) + perseguição (limitada aos motivos estabelecidos na lei: raça, religião, nacionalidade, etnia, opiniões políticas). Acreditamos que, muitas vezes, o sentimento de ameaça e temor experimentado por um determinado indivíduo, ainda que legítimo, pode não encontrar sustentação correlata nas normas de um país, ou mesmo a percepção quanto à perseguição sofrida não auferir adequação aos termos da lei.

Esses exemplos ajudam a demonstrar a complexidade a ser enfrentada pelo solicitante de refúgio diante do longo processo burocrático-legal que ele terá à sua frente.

Ao emaranhado de sentimentos e às adversidades proporcionados pela situação de refúgio vão somar-se as questões problemáticas do país de asilo. No Brasil, algumas, já recorrentes para os nacionais, acabam se estendendo aos imigrantes, como aquelas relacionadas com as desigualdades de raça e classe social, por exemplo.

Todos os relatos dão conta de dificuldades experimentadas, em algum momento, em razão da cor da pele, da condição social ou da nacionalidade, seja na busca por emprego, seja no contato com agentes públicos responsáveis pela tramitação de documentação e legalização como nas falas abaixo:

Uma coisa que existe é a nossa diferença de refugiados africanos... Vamos dizer, eu, especificamente, como angolano, o que nós constatamos sempre é que existe um tratamento diferente em relação a, vamos dizer, sírios, ou refugiados europeus, por exemplo. O tratamento com essas pessoas é mais amistoso, tanto na sociedade, como nas próprias instituições. (...) Nós tivemos muita dificuldade em adquirir emprego. Na construção civil, muitos [angolanos] vieram com qualificação e não eram aceitos em algumas instituições. Mas eu vejo sírios e alguns de outros lugares, eles conseguiram ser inseridos à sociedade brasileira de uma forma muito mais fácil. (J.F., entrevista exploratória, junho de 2018, Centro, RJ)

J.P. relata:

Quando eu cheguei, eu fiquei assustado. Eu confesso que eu queria voltar na primeira semana... Fiquei assustado, aterrorizado com a violência que eu encontrei na época. Eu acho que eu sofri mais aqui do que lá. Independentemente do que aconteceu lá, [eu] tinha um aparato de família, tinha mãe, tinha um colo. Aqui, não. Aqui eu sou sozinho. Aqui eu e Deus, mais ninguém. Aqui, se você chorar, tem que chorar calado. (J.P., entrevista exploratória, junho de 2018, Glória, RJ)

A violência a que J.P. se refere diz respeito ao tratamento dado pelas pessoas, no geral, ao estrangeiro nessas condições: asilado, carente, necessitado. A violência do 
preconceito e da discriminação que se apresentam, ora de forma direta, ora de forma velada.

A "Teoria do Preconceito Flagrante e Sutil"7, desenvolvida a partir do final da década de 1980, auge da diáspora angolana, esclarece essas duas diferentes formas de manifestação e seus componentes:

Preconceito flagrante: é o preconceito de toda a vida, "forte, próximo e direto", e consta de dois componentes: percepção ameaçante do ex grupo, com o conseguinte rechaço a este, e a oposição ao contato íntimo com os membros do ex grupo.

Preconceito sutil: é "frio, distante e indireto" e consta de três componentes: defesa dos valores tradicionais, exageração das diferenças culturais e negação das emoções positivas. [aspas e grifos acrescentados] (Oliveira, 2015, p. 431, ).

No preconceito flagrante, o componente "percepção ameaçante", consiste no sentimento ou percepção, por parte de um dado grupo ou sociedade, de ameaça, desvantagem ou perda de espaços e privilégios em razão da presença de determinada pessoa ou grupo, e que vai resultar no rechaço e no reforço de crenças que buscam argumentar e explicar o prejuízo ou inconveniência que essa(e) pessoa/grupo causa à sociedade como todo, como uma justificativa para o preconceito, ou uma forma de negá-lo (Oliveira, 2015).

Já na forma sutil, o componente que trata da "defesa dos Valores Tradicionais", está mais relacionado com a intolerância e a não aceitação das diferentes formas de pensamento, comportamento e convivência, produtos de práticas culturais distintas. O segundo componente do preconceito sutil, a "exageração das Diferenças Culturais" é mais perverso, na medida em que essas diferenças de fato existem, mas, no preconceito sutil, são utilizadas como forma de inferiorização e intensificadas "por meio de estereótipos" (Oliveira, 2015, p. 433).

Esses elementos estão presentes e são facilmente identificáveis nos discursos e argumentações que embasam os debates sobre raça, nacionalidade, sexualidade, ideologia política e outros temas complexos ou polêmicos. No dia a dia do refugiado que conversamos, esses componentes aprofundam os obstáculos e reveses da busca por integração e inclusão na vida social local. Como narra P. um episódio ocorrido com ela:

Uma vez só, na universidade, que uma colega (...) levantou e disse que eu estava a ocupar espaço de um brasileiro. Eu disse pra ela: não, eu não estou a ocupar espaço, até porque aqui na turma são 32 cadeiras ou carteiras, - e nessas 32 nós só éramos 20 ou 18. Então, eu não estou a ocupar espaço. Eu pago a faculdade, não é de graça. Então, se eu estou a ocupar espaço, o próprio brasileiro também vem e ocupa, porque, eu não tenho culpa. Aqui, quem tem dinheiro, paga. Eu não estou a 
tirar nada vosso. Eu estou a vos dar. (P., entrevista exploratória, junho de 2018, Glória, RJ)

A.M. também passou por situação similar. Ela conta que:

Eu estava numa fila para vaga de emprego. Então, eles trouxeram uma ficha pra que fôssemos preenchendo, ali mesmo, ainda, na rua. Fiz uma pergunta ao rapaz que entregava os papéis e, depois de ouvir o meu sotaque, eu acho, né, porque eu não tinha falado nada, uma mulher na fila começou a falar com a outra: "essa gente sai lá da terra deles pra vir tirar nosso emprego aqui. Já tá bem difícil aqui pros brasileiros, sem gente de fora". Eu fiquei a olhar pra ela, mas não disse nada, porque..., né. De quê ia adiantar? (A.M., entrevista exploratória, abril de 2018, Copacabana, RJ)

Aos novos sujeitos - seus critérios, subjetividades e idiossincrasias - com os quais o refugiado precisa confrontar-se, também o lugar, a cidade - seus costumes - atua como um outro, que estabelece o embate entre universos divergentes e convoca a novas formas de ser e de agir no mundo, desafiando, ao longo do processo de adaptação, o habitus, que cada um dos refugiados traz consigo ${ }^{8}$. Assim, alguns dos entrevistados se colocam como cansado com problemas que precisam ser enfrentados e resolvidos; da dependência da aceitação das pessoas; dos diferentes costumes nos quais eles não estão inseridos e que acabam atuando como mais uma coerção ao processo de adaptação.

Ainda que determinados costumes ou diferenças possam parecer banais e, até insignificantes, para o refugiado eles se apresentam como um desafio para os seus valores e crenças. J.F. narra um de seus primeiros estranhamentos no Rio de Janeiro:

Nós temos uma educação, digamos, muito rígida, que nós preservamos muito. Por exemplo, o respeito do mais novo com o mais velho. (...) Eu ficava muito chocado, na escola (...) de como os meus colegas se dirigiam aos nossos professores. Eu ficava assim: Nossa! Como é que ele fala isso ao professor!? Nós fomos educados que professor é, depois do pai e da mãe, você tem que abaixar a cabeça pra ele! Você tem que obedecer, tem que falar com respeito. (...) Eu chegava em casa, comentava: aqui é assim, eles não têm respeito. Tratam os adultos do mesmo jeito que eles tratam um amigo. Mas, fui me acostumando... São culturas diferentes. (J.F., entrevista exploratória, julho de 2018, Centro, RJ)

A convivência com outro povo desvela qualidades e/ou diferenças próprias de seu próprio povo ou nação de origem, não percebidas anteriormente, posto que é o contraste com as alteridades que permite que elas se manifestem, ou sobressaiam. E.G., um dos entrevistados comenta: 
É algo que faz parte da cultura do povo, do país por um todo. Muitos desses hábitos são coisas negativas, tipo... enganar, entendeu? Isso é uma coisa bem angolana e até um pouco, também, assim, africana. (...) Enganar, enrolar. O angolano é difícil, (...) Por ele ter passado muita dificuldade... Então, que que acontece? Ele pode chegar aqui e te falar: "Pô, quer me vender esse telefone? Amanhã mesmo eu vou receber, e vou te pagar". Sendo que ele não tem dinheiro nenhum pra receber amanhã. Eu não sei qual a dificuldade do angolano! $O$ angolano, ele não consegue comprar uma coisa, parcelar em 10 vezes, e todo mês pagar. (...) Esses comportamentos, se você for na comunidade Vila do João ${ }^{9}$, onde vive os angolanos, esse é o comportamento em muitos deles, não pensar muito no outro, entendeu? É algo complicado! Você não está falando só de um jovem, tá falando, às vezes, de cara de 60 anos, que tá num bom cargo. Os políticos de lá, pô, isso é a postura, basicamente, do país. (E.G., entrevista exploratória, julho de 2018, Cinelândia, Centro, RJ)

\section{A.M. corrobora essa visão:}

Convivo muito com os angolanos, tenho amigos... Mas, não dá pra confiar, não. No caso, assim, né... de compromisso, trabalho... dinheiro, então!!! Nem se fala!! Quando querem alguma coisa, estão sempre a te ligar, depois que já fizeste o que queriam, já não te retornam. Mentem. Se tu encontras com eles depois, dizem que perderam o seu contato.... É assim. Não dá pra confiar. (A.M., entrevista exploratória, abril de 2018, Copacabana, RJ)

Aos hábitos culturais, é preciso acrescentar os burocráticos e institucionais, já que é a partir da relação com eles que o imigrante poderá ter acesso ao status necessário para uma vida legal dentro do país de asilo. Assim, cabe conhecer um pouco das trajetórias vividas, neste âmbito, por esses angolanos no Rio de Janeiro.

E.G. é um dos mais contundentes com relação aos tratamentos dispensados aos solicitantes de refúgio. Ele chegou ao Brasil com 10 anos, em 1992, e hoje (2017) tem visto de permanência, concedido em 2008 e com validade até 2018. Porém, durante 14 anos - dos 12 aos 26 - precisou se submeter à Polícia Federal para renovação do seu status de refugiado. Ele relata, com extrema indignação:

(...) A gente tinha um documento de refugiado que tinha que renovar de 6 em 6 meses... Realmente isso aí era uma coisa que, psicologicamente, era uma humilhação muito grande. Não pelo intuito de ter que renovar, mas de como era a renovação... de como era o tratamento do pessoal da Polícia Federal. De como era, não, de como é até hoje! [Pergunto: Como é?] Horrível!!! Horrível! Humilhação! Os caras só faltam chamar você de cocô, cala a boca!!! (...) hoje, eu fico feliz de não ter mais que passar por esse processo. Por eu ter o documento permanente, então, eu renovo a cada dez anos. Porque, mesmo você indo lá, quando não é com você, você vê com pessoas de outra nacionalidade. E aí 
você vê que esse mau tratamento é esculachante mesmo! Não é mau atendimento. É realmente humilhação o que as pessoas passam lá! Principalmente negros! Principalmente africanos! Porque hoje têm refugiados que vêm já da América do Sul e tal, assim branquinhos, né, então, os caras dão um tratamento um pouco menos áspero. Mas, quando é com africanos tudo que os caras fazem é algo, realmente, de muita, muita, muita humilhação! Tudo é agendamento. Os caras agendam. Você chegou lá, se o cara tiver estressado... não acordou bem, ele te manda voltar. E se vocêfalar: mas eu não posso voltar, tô precisando do documento, eu tenho que tirar a carteira de trabalho, o cara te xinga, chama de macaco. É realmente, assim, algo muito grave que acontece ali. (E.G., entrevista exploratória, julho de 2018, Cinelândia, Centro, RJ)

Um pouco exaltado, ele prossegue:

(...) Aí tinha aqueles caras que você já sabia, que você ia lá, falava com os caras assim, mansinho, por quê? Porque você depende da documentação. Então, se você chegar lá, e, tipo assim, quiser bater de frente, cobrar um mínimo de respeito lá, você só se prejudica mais, porque é uma forma de agir de grande maioria, é $90 \%$ lá que faz esse atendimento e age assim. Então, o cara não tem o receio de te falar nada na frente de todo mundo, porque os outros também agem da mesma forma, entendeu? Então, se você quiser questionar alguma coisa, quando a gente vai passar para outro módulo, o outro lá vai ver que você retrucou aqui, por uma coisa que você tá certo, que você tem razão, mas ele vai querer te dar não. Isso aí dava vontade de você retornar pro seu país, passar a necessidade que tivesse que passar lá, porque, você tirar um dia todo... Pra tratar desse documento levava o dia todo! O dia todo sem comer! O dia todo sendo humilhado. O dia todo você passando, vendo teus irmãos passando, sabe...? (E.G., entrevista exploratória, julho de 2018, Cinelândia, Centro, RJ)

E.G. conta, ainda, que é comum, na Polícia Federal, depois de horas de espera, os solicitantes serem passados pra trás no atendimento por despachantes, que, com a facilitação atendentes, recebem o privilégio do atendimento prioritário, o que, não raro, resulta no retorno do imigrante para casa sem ter sido atendido. Ele acrescenta:

Eu cheguei até a pensar em mandar para uma reportagem. A pessoa te chama de merda.... "Você tinha que ir lá para guerra, não sei o quê lá!" O cara comenta: "Ah! Esses macacos vêm pra cá!!!” Pô, é algo que... Quando começa a chegar, de 6 em 6 meses, você não pensa no ônibus que tem que pegar, (...) você só pensa em como vai ser tratado. Será que vai ser pior que da outra vez? (E.G., entrevista exploratória, julho de 2018, Cinelândia, Centro, RJ)

E completa: "De tudo que eu vivi aqui, se tem algo que eu quisesse uma reparação, não dá! isso tem que mudar! seria esse ponto. De tudo" (E.G., entrevista exploratória, julho de 2018, Cinelândia, Centro, RJ). 
Os relatos evidenciam as dificuldades colocadas para o refugiado no período de ajustamento a uma comunidade e/ou lugar. E, na medida em que do seu comportamento depende a sua inserção no convívio social, ele se vê defrontado com um dilema:

(...) deve escolher entre padrões incompatíveis uma solução conveniente. Por causa da escolha, as situações que deve enfrentar são situações problemáticas. E em consequência sua conduta revela sérias alternativas, ora aceitando, ora repelindo um determinado padrão de comportamento ou um valor qualquer. O próprio indivíduo avalia-se sob dois pontos de vista diferentes e sofre as consequências do embate da lealdade que devota ou julga que deve devotar relativamente a cada grupo em presença. (Fernandes, 2007 p. 293)

Dessa forma, mesmo que transitória, a fase de adaptação é marcada por contradições que impõem aos sujeitos uma reorganização de suas crenças, seus hábitos e valores, a uma reformulação de si.

Nesse quadro, se, do prisma jurídico, estar refugiado acarreta uma série de condutas e ações públicas que podem (deveriam) proporcionar certo grau de proteção e inclusão aos/ dos sujeitos nesta condição, ser refugiado, ao contrário, é a amplificação do sentimento de desamparo porque se apresenta como uma marca, ainda que invisível, de uma diferença negativa, inferiorizante, um estigma. Erving Goffman (1988) explica que o termo foi criado pelos gregos

(...) para se referirem a sinais corporais com os quais se procurava evidenciar alguma coisa de extraordinário ou mau sobre o status moral de quem os apresentava. Os sinais eram feitos com cortes ou fogo no corpo e avisavam que o portador era um escravo, um criminoso ou traidor - uma pessoa marcada, ritualmente poluída, que devia ser evitada, especialmente em lugares públicos. (p. 11).

Com o tempo, o termo passou a ser mais empregado com referência à própria desgraça do que a traços corporais. Goffman identifica três diferentes tipos de estigma. O primeiro relacionado com as deformidades físicas de determinados sujeitos, e visíveis aos outros; o segundo relacionado com a virtude, como vontade fraca, desonestidade, por exemplo, e, por fim, os estigmas tribais de raça, nação e religião, que têm o atributo de poderem ser disseminados por gerações.

O estigma é um construto social utilizado para diferenciar, inferiorizando por meio de termos específicos (Goffman, 1988), como aleijado, bastardo, retardado ou, preto, africano, refugiado. Definidos, esses atributos, ou estereótipos, se impõem e ganham contornos de uma verdade universal que se sobressai em relação a outros traços do sujeito, que, não raro, acaba sendo contaminado pela crença social em relação a ele. 
Da mesma forma, o atributo refugiado vai, aos poucos, sendo internalizado pelos sujeitos como uma marca. Mais do que um rótulo, uma característica de sua própria identidade.

E.G., ainda se referindo aos anos de humilhação na Polícia Federal para renovação de documento, ajuda a ilustrar como os atributos transformam-se em sentimentos:

No início, a coisa ficava um pouco mais assim, tipo: eu nasci num país de miseráveis, eu sou um miserável, então, eu tenho que aceitar esse esculacho, eu sou um coitado. Você se colocava, assim, com muita tristeza. Só que depois que você vai crescendo, vai tendo informação, vai estudando, vai aprendendo, aí começa a ver a coisa já com revolta, como questão mesmo de injustiça. (E.G., entrevista exploratória, julho de 2018, Cinelândia, Centro, RJ)

Além disso, as normas e os procedimentos burocráticos se fundamentam na lógica da diferença, portanto, o imigrante precisa ser diferenciado dos demais. Assim, fora a diversidade natural, seja ela de cor ou nacionalidade, o imigrante carrega consigo, quando já os tem, documentos que reforçam a sua condição de diferente, como é o caso da Carteira de Identidade: Categoria - REFUGIADO, que o solicitante de asilo recebia, até recentemente, como o documento de identificação que deveria ser utilizado em seu trânsito dentro do país de asilo e que, segundo relatos, causava uma série de constrangimentos. E.G. narra a sua versão:

(...) Durante muitos anos, no lugar da classificação vinha escrito refugiado. Isso era algo, também, bem complexo. (...) Por exemplo, na primeira empresa que eu trabalhei, uma vez eu fui tirar cópia, o documento caiu, um colega meu pegou e saiu correndo pela empresa toda falando: "ó o neguinho refugiado, aí!". É algo realmente constrangedor. Porque a palavra refugiado, aqui no Brasil, pelo menos eu enxergo, tenho a noção de que ela tem uma conotação negativa. Eu acho. Pejorativa. (...) E isso é uma identidade. É uma não! Isso é a identidade! Então eu evitava mostrar. Quando tirei a habilitação eu praticamente encostei a identidade de estrangeiro, (...) e usava a $\mathrm{CNH}$ e a Carteira de Trabalho. Porque existia... existia, não! Há um preconceito muito grande quando se fala a palavra refugiado. (...) Você ser negro no Brasil, só quem é que sabe. Você ser negro no Brasil, estrangeiro, só quem é que sabe. Você sendo africano?! Só quem é que sabe. (E.G., entrevista exploratória, julho de 2018, Cinelândia, Centro, RJ)

Apesar disso, a resolução dos problemas jurídicos relativos à identidade documental é sempre recebida como uma grande conquista. Em seu relato, colhido em 2018, L.P., que chegou ao Rio de Janeiro em 1999, conta que: 
(...) Felizmente, há 3-4 anos atrás, eu acho, 4-5 anos atrás, consegui o meu nome de volta. [O que muda?] Primeiro muda tudo. É uma grande autoafirmação, por você ser você mesmo: eu sou isso!! [Você antes não era, então?] Não, não. Antes, você ficava dividido. Na verdade, você representava uma coisa e você não era a coisa que você quis ser, ou que você é totalmente. É... Você quando usa um nome que não é teu, por circunstâncias da vida... acaba você não se aceitando. E quando você volta, novamente, pras tuas origens, pro teu nome, tudo aquilo que é teu, então, é uma felicidade muito grande. É uma auto-afirmação, uma vontade de você querer vencer... Você consegue, dali, dar os nomes pros teus filhos... é uma sensação inexplicável. (L.P., entrevista exploratória, maio de 2018, Lapa, RJ)

A terceira filha de L.P. nasceu exatamente no momento em que ele conseguiu receber a documentação que legalizou sua permanência no Brasil. Ele declara, emocionado: "Minha filha nasceu junto com a minha legalização. Dei a ela o nome: Tchinossole Vitória". Ele explica que Tchinossole é um termo do dialeto umbundu que significa "o que eu mais queria".

O indivíduo da diáspora e na categoria de refugiado carrega, então, essa marca - estrangeiro, africano, refugiado que o diferencia dos nacionais. Ele é, também, o produto da mistura de costumes, tradições e comportamentos aos quais vai sendo exposto, e dos significados que lhes atribui. Isso, porém, não lhes impõem um lugar apenas de vítimas do sistema de migração e exceção na nova sociedade. Os refugiados diante das adversidades criam estratégias de sobrevivências e rede de articulações e ajuda mútuas. Além disso, são em sua maioria, cientes das leis que os garantes direitos em solo estrangeiro. As redes de ajuda mútuas, criadas entre os refugiados, são utilizadas, muitas das vezes, como lugar de encontro para falar sobre suas lutas, dificuldades, estratégias de emprego e relembrar suas memórias. Assim, a memória será um elemento relevante - talvez, mesmo, vital - , do sentimento de "continuidade e coerência desse grupo, fortalecendo a manutenção de uma identidade cultural ou coletiva, capaz de garantir unicidade frente à exposição dos sujeitos ao entrelaçamento de valores, crenças e costumes a que estarão submetidos (Pollak, 1992, p. 204).

\section{Memória como referência, resistência, pertencimento e identidade}

Se a memória é um elemento importante na construção e preservação da identidade, o relato autobiográfico é não apenas a narração de lembranças, mas a própria identidade do sujeito sendo reconstruída a partir das recordações e narrativas (Pollak, 1992). Toda lembrança é, com efeito, uma reconstituição do passado ancorada em elementos do presente. Nas palavras de Henry Rousso (2006), memória é 
"a presença do passado", " uma reconstrução psíquica e intelectual que acarreta de fato uma representação seletiva do passado" (Rousso, 2006. p. 94).

No caso do grupo de refugiado, os sujeitos, no processo de refúgio e a necessidade de abandono da pátria mão, se ver obrigado a abrir mão de tudo o que o delineava como indivíduo e ao qual reconhecia como seu - nação, casa, família, tradições - o que resta é a memória, suas lembranças. Mesmo que elas, por serem articuladas no presente e, portanto, eivadas de seus elementos, possam não espelhar uma reprodução fidedigna dos fatos.

É certo que, ao emigrarem, os angolanos rompem com os espaços físicos que, por meio de certo grau de permanência e estabilidade, comumente presentes nos "quadros espaciais" de memória, sustentam memórias e relações de grupos, e cujas ambiências se apresentam como referência aos sujeitos, porque nelas se dão todas as formas de experiências, inclusive a de transmissão de lembranças. Segundo Halbwachs, "quando um grupo humano vive muito tempo em um lugar adaptado a seus hábitos, não somente os seus movimentos, mas também os seus pensamentos, se regulam pela sucessão das imagens que lhes representam os objetos exteriores." (2003, p. 163).

Entretanto, tomando como base os argumentos de Halbwachs (2003), Santos (2017), aponta que alguns espaços sequer se apresentam sob uma forma física concreta, como uma casa, uma rua, mas, como grupamentos - jurídicos, religiosos, econômicos - cuja base espacial se apresentaria, respectivamente, sob as formas de direitos e obrigações, crenças, e relações de produção, e nos quais se formam determinados valores, opiniões e comportamentos, e que estariam carregados de marcas nossas e dos outros, expressando traços de um determinado grupo. Assim, podemos observar que as redes construídas pela comunidade angolana no Rio de Janeiro, ainda que nem sempre se estabeleçam em espaços físicos, mostram-se ambientes de convivência nos quais hábitos tradicionais são reproduzidos, e, também, novos valores e costumes são construídos, além de serem lugares onde as estratégias de sobrevivências são contadas e recriadas.

É na memória que se encontram os elementos que permitem aos sujeitos uma ordenação da vida, do mundo, permitem colocar em ordem o passado e distingui-lo do presente, dar conta das temporalidades através de um processo que é, também, de classificação do que recordar e do que esquecer, "uma vez que a memória é compreendida a partir de um processo seletivo que envolve tanto o lembrar quanto o esquecer" (Santos, 1993, p. 71).

Assim sendo, nas participações em eventos foi possível, a partir da observação participante, perceber a presença desses elementos indenitários que a memória traz. À exceção dos ritos religiosos (posto que esses costumam solicitar ocasião 
específica): comidas típicas angolanas, músicas e danças, bem como trajes africanos utilizados por vários participantes.

Esses costumes se manifestam no dia a dia dos imigrantes, que buscam, por meio de sua reprodução, reiterar sua identidade nacional e dar continuidade ao legado cultural de seus antepassados. Perguntado sobre o que sobra de tantas rupturas e perdas, J.F. responde que:

Sobra muita coisa. É uma coisa que está muito enraizada. (...) E, em casa, nós preservamos o máximo possível as nossas tradições, os nossos hábitos, na alimentação, em alguns vestuários tradicionais. [Comento sobre o sotaque forte, tendo em conta que ele já vive no Brasil há 25 anos]. É uma coisa que fizemos questão de não perder, porque é nossa identidade. As pessoas têm que saber de onde você vem. Então, isso é uma marca registrada nossa. (J.F., entrevista exploratória, julho de 2018, Centro, RJ)

De fato, muito dificilmente se encontra um angolano livre de seu sotaque de origem. Mesmo os que chegaram aqui ainda pequenos.

Cabe ressaltar que são poucos os espaços na cidade para preservação e prática dos hábitos e costumes do país africano. Além do Centro Cultural de Angola, que fica no centro da cidade e faz parte do Consulado daquele país, manifestações culturais angolanas acontecem, também, no Dikanza, casa noturna na Lapa, e em uma barraca na Rua Uruguaiana, que vende alguns produtos de Angola e serve de local de encontro.

De um lado, os angolanos se ressentem da escassez de espaços e investimentos que promovam a sua cultura nacional dentro do país de asilo, e não reconhecem os existentes como satisfatórios:

Nossa cultura não é cultivada. Se você vem num espaço como este [refere-se ao Centro Cultural do Consulado de Angola]... Isso é uma mutilação da nossa cultura africana... Aqui é a forma politicamente correta de falar, a forma bonita, forma que todo turista vê. Mas a realidade é muito diferente disso. A realidade somos nós. A realidade é meus filhos, a realidade é outros irmãos. (J.P., entrevista exploratória, junho de 2018, Glória, RJ)

Entretanto, o próprio J.P., que é proprietário de um do espaço na Lapa, reconhece:

Ainda, você sente um pouco de resistência. Na verdade, essa resistência ainda é do
próprio angolano. (...) Uns não têm capital para estarem aqui, outros não vêm porque
têm outros objetivos. Os poucos que vêm, não têm sempre o hábito de vir. Na verda-
de, é um trabalho de resgate que se está a fazer pra trazer essas pessoas à própria ori-
gem. É um trabalho que você não vai fazer de hoje pra amanhã. (J.P., entrevista
exploratória, junho de 2018 , Glória, RJ) 
Por mais que parte da comunidade angolana rejeite as manifestações institucionais que buscam celebrar datas relevantes para o país, como as que ocorrem no Consulado de Angola no Rio de Janeiro, na medida em que reproduzem hábitos e costumes comuns e se apresentam como espaços de celebração memorial, por meio de peças nacionais, como fotografias, pintura, tecidos, entre outras, os espaços institucionais e seus eventos são uma garantia de manutenção e transmissão de parte da memória cultural desse povo, ainda que apenas aquela selecionada pelo olhar e pela lógica oficias.

Porém, é mesmo no âmbito familiar ou de pequenos grupos que memória e práxis culturais desses imigrantes são compartilhadas entre nacionais, e reproduzidas e transferidas aos seus descendentes. As memórias apresentam-se interligadas entre os indivíduos; a família seria um local privilegiado de transmissão memorial, e a memória de grupo, em sua estrutura, se basearia na transferência familiar da experiência corporificada para a geração seguinte (Assman, 2011).

No caso dos angolanos que foram estudados neste artigo, a comida e a música aparecem como os itens culturais de maior importância nessa transferência familiar e de grupo longe da nação de origem, além dos valores morais tradicionais de comportamento. Finalizando, cabe ressaltar, que a cultura alimentar trazida pelos escravos para o Brasil favorece muito o cotidiano desses angolanos, já que muitos dos alimentos consumidos em seu país podem ser facilmente, particularmente nos Estados de Minas e Bahia. Mesmo no Rio, é possível encontrar a matéria prima necessária para preparar seus pratos tradicionais, como nas palavras de L.P.

Não é muito diferente, (...) Então, você consegue comer um funge ${ }^{10}$ de caruru, conse-
gue comer uma canjica de milho, consegue comer um mufete ${ }^{11}$. Você consegue fazer
uma bebida tradicional que é a kissangua ${ }^{12}$, consegue fazer de arroz, consegue fazer
com folhas de abacaxi... Quer dizer, então, são coisas que os pais e os avós produziam
artesanalmente dentro de casa. (L.P., entrevista exploratória, maio de 2018, Lapa, RJ)

\section{Conclusão}

Este artigo procurou entender, a partir da categoria de refugiado, a vivência de um grupo de angolanos na cidade do Rio, levando-se em conta suas trajetórias na cidade, as dificuldades como refugiados e demonstrando a importância da concepção de memória coletiva apontada por por Halbwachs (2003), na qual, a lembrança do passado buscada pelo presente se constitui como elemento importante na manutenção do grupo e da identidade angolana. Seriam as redes de refugiados angolanos um canalizador dessas memórias e, por conseguinte, um espaço de manutenção de suas tradições e identidades. 
Ainda a despeito da memória, no caso estudado neste artigo, pode-se admitir, partindo de Halbwachs, que as memórias se desenvolvem e se reconstroem a partir de laços de solidariedade estabelecidos por meio de elementos simbólicos compartilhados, sendo, ainda, capaz de organizar as relações sociais - compartilhamento, pertencimento e solidariedade. Assim, tanto sob o aspecto do individual, quanto do grupal, a memória - e as práticas dela recorrentes - parece ser um dos elementos fundamentais para construção da identidade como refugiado, sem, no entanto, abrir mão de suas raízes e tradições. Ou seja, a memória atuaria como elemento estratégico na formação de redes de sociabilidade e ajudaria os refugiados angolanos no processo de ressocialização no lugar de refúgio. A memória desse grupo serviu como base para a reprodução dos hábitos e costumes que, no dia a dia, irão proporcionar aos refugiados o sentimento de pertencimento a uma família, a um lugar, a uma tradição, a uma história, remanescentes e remotos.

Pode-se afirmar que, mais do que um status político, o refúgio se apresenta para o grupo aqui analisado, como uma marca, um traço identitário que os acompanha durante toda a sua permanência no país de asilo, mesmo depois que sua condição legal os autoriza à residência permanente, ato que agiliza a vida prática, porém, não desfaz, em alguma media certos estigmas atribuídos aos refugiados.

Foi possível, através das entrevistas exploratórias e da participação em algumas das atividades culturais e festivas, perceber falas e narrativas contraditórias e conflitantes no interior do grupo de refugiados estudado. Sentimentos de fragilidade, de insegurança e às vezes de revolta, apontados como sinais de uma identidade inferiorizada se misturavam a uma supervalorização da própria imagem, do orgulho à cultura angolana e suas tradições. É presente nas narrativas dos membros desse grupo uma crença em que as dificuldades de suas vidas os fazem superior em relação aos demais, e que se revela em falas como "quem não passou por isso, não sabe o que é viver", " quem não sofreu, não cresceu”, " quem não viveu uma guerra, não sabe o que é dificuldade", e que, não raro, aparecem, tanto nas narrativas colhidas, como na postura física e nas conversas informais nos eventos observados.

No âmbito institucional, o Consulado de Angola é a entidade responsável pelas tratativas referentes aos e/imigrantes do país, porém, como sugere algumas das entrevistas exploratórias, o órgão parece não contar com a confiança de seus nacionais, que o utilizam por necessidade extrema e falta de opção, já que, de modo geral, a comunidade angolana na cidade, em especial aqueles em situação de refúgio, se ressente de um comprometimento maior por parte da instituição em relação a eles, no sentido de mais informação, mais apoio, acompanhamento e proteção. 
Quanto às instituições brasileiras, tendo como parâmetro as narrativas dos refugiados angolanos, observa-se que as leis voltadas para a migração e o refúgio, mesmo quando bem consistentes e bem intencionadas, reproduzem, por intermédio dos encarregados de sua operacionalização nos diversos órgãos, uma lógica que apontam para atitudes racistas e xenofóbicas que, em certa medida, reflete o preconceito arraigado na sociedade, deixando evidente o quanto se precisa avançar em termos de políticas públicas e de uma capacitação mais humanizada para o atendimento a esse público, mesmo que alguns relatos, afortunadamente, destaquem a solidariedade encontrada e recebida na cidade, tanto das pessoas, quanto de algumas entidades religiosas, em especial a Cáritas Arquidiocesana.

\section{Notas}

Por decisão pessoal, a autora e o autor do texto escrevem segundo o novo acordo ortográfico.

1 Apresentação do Ministério da Justiça e Segurança Pública, Governo Federal Brasil: Refúgio em Números - $4^{a}$ edição. Disponível em https://www.acnur.org/portugues/wp-content/uploads/2019/07/Refugio-em-n u\%CC\%81meros_versa\%CC\%83o-23-de-julho-002.pdf

2 Apresentação do Ministério da Justiça e Segurança Pública, Governo Federal Brasil: Refúgio em Números - $4^{\mathrm{a}}$ edição. Disponível em https://www.acnur.org/portugues/wp-content/uploads/2019/07/Refugio-em-n u\%CC\%81meros_versa\%CC\%83o-23-de-julho-002.pdf.

3 Ver principalmente os capítulos em The Oxford Handbook of Refugee and Forced Migration Studies (Fiddian-Qasmiyeh, Loescher, Long \& Sigona, 2014) e em Fluxos Migratórios e Refugiados na Atualidade (Woischnik, 2017).

4 São eles: Progenitor sozinho; Mulher sozinha; Criança não acompanhada; Criança separada; Criança chefe de família; Criança perdida; Pessoa idosa encarregada de menores; Pessoa idosa sozinha; Doente mental; Deficiente físico; Amputado; Doente crônico; Surdo e/ ou mudo; Cego; Sobrevivente de violência.

5 Este Laboratório está vinculado ao Programa de Mestrado em Sociologia Política da Universidade Candido Mendes. Nele, diversos projetos em torno da temática - cidade, cultura, urbanização e populações vulneráveis vem sendo desenvolvidos. A situação dos refugiados angolanos na cidade do Rio de Janeiro também foi objeto de pesquisa do LECC.

6 Atendimento humanitário são assentamentos construídos por organizações internacionais e/ou organizações não-governamentais (ONGs). De caráter provisório, são locais com estrutura precária, constituída basicamente de tendas ou barracas, onde se busca operar ações de emergência para higiene pessoal, suprimentos médicos e alimentação. 
7 Ver Meertens e Pettigrew (1997) e Dolvidio e Gaertner (1986).

8 Ohabitus aqui é entendido na concepção de Norbert Elias, um conjunto de predisposições incutidas no sujeito e que se manifestam no agir, na personalidade e em sua visão de mundo (Elias, 1993).

9 Vila do João é uma das 17 favelas que compõem o Complexo da Maré, Conjunto Habitacional erguido pelo Projeto Rio, do Governo Federal, no início da década de 1980. Seu nome faz homenagem ao General João Baptista de Figueiredo, Presidente da República por ocasião de sua criação.

10 Mistura de farinha de mandioca ou milho com água, que resulta em uma espécie de purê.

11 Peixe assado com banana-da-terra e mandioca.

12 Espécie de refresco que pode ser feito à base de milho verde ou de casca de ananás com açúcar mascavo e gengibre.

\section{Referências}

Agier, M. (2006). Refugiados diante da nova ordem mundial. Tempo Social, revista de sociologia da USP, 18(2), 197-215.

Assman, A. (2011). Espaços da recordação: formas e transformações da memória cultural. Campinas, SP: Editora Unicamp.

Bauman, Z. (2017). Estranhos à nossa porta. Rio de Janeiro: Zahar.

Cáritas Brasileira (2007). Relatório Anual 2006. São Paulo: CB.

Cáritas Brasileira (2008). Relatório Anual 2007. São Paulo: CB.

Cierco, T. (2017). Esclarecendo conceitos: refugiados, asilados políticos, imigrantes ilegais. In J. Woischnik (Ed.), Fluxos Migratórios na Atualidade (pp. 11-25). Rio de Janeiro: Fundação Konrad Adenauer Stiftung.

Dolvidio J., \& Gaertner, S. L. (1986) Prejudice, Discrimination and Racism. Orlando: Academic Press.

Elias, N. (1993). O processo civilizador. São Paulo: Zahar.

Fernandes, F. (2007). Tiago Marques Aipobureu: um bororo marginal. Tempo Social Revista de Sociologia da USP, 19(2), 293-323.

Fiddian-Qasmiyeh, E., Loescher, G., Long, K., \& Sigona, N. (Eds.) (2014). The Oxford handbook of refugee and forced migration studies. Oxford, Inglaterra: Oxford University Press.

Gersztein, P. C. (2017). O antidecisionismo de Hannah Arendt: o pensamento arendtiano como crítica à teoria decisionista de Carl Schmitt. São Paulo: Editora Fi.

Goffman, E. (1988). Estigma: notas sobre a manipulação da identidade deteriorada. Rio de Janeiro: LTC.

Goodwin-Gill, G. S. (2014). The international law of refugee protection. In E. Fiddian-Qasmiyeh, G. Loescher, K. Long, \& N. Sigona (Eds.), The Oxford handbook of refugee and forced migration studies (pp.1-14). Oxford, Inglaterra: Oxford University Press. Disponível em 
https://www.oxfordhandbooks.com/view/10.1093/oxfordhb/9780199652433.001 .0001/oxfordhb-9780199652433-e-021?print=pdf

Halbwachs, M. (2003). A memória coletiva. São Paulo: Centauro.

Hall, S. (2000). Quem precisa de identidade? In T. T. da Silva (Org.), Identidade e diferença: a perspectiva dos estudos culturais (pp. 103-132). Petrópolis: Vozes.

Jubilut, L. L., \& Godoy, G. G. de (Orgs.) (2017). Refúgio no Brasil: comentários a Lei 9.474/97. São Paulo: Quartier Latin/ACNUR.

Marques, R. (2001). La guerra como una forma de vida. Revista El Fusil Roto, (49) Disponível em https:// wri-irg.org/es/story/2001/la-guerra-como-una-forma-de-vida

Meertens, R., \& Pettigrew, T. F. (1997). Is subtle prejudice really prejudice? Public Opinion Quartely, 61(1), 54-71.

Moniz, F. (2018). Libertação e independência de Angola: a participação da Tanzânia na independência de Angola. Rio de Janeiro: Artprint.

Oliveira, D. R. de (2015). Preconceito: tendências históricas e abordagens contemporâneas. In J. d'Adesky, \& M. T. Souza (Orgs.), Afro-Brasil: debates $\mathcal{E}$ pensamentos (pp. 321-342). Rio de Janeiro: Cassará editora.

Pearce, J. (2017). A guerra civil em Angola (1975-2002). Lisboa: Tinta Fresca.

Pinto, J. P. H. (2016). A identidade nacional Angolana - Definição, construção e usos políticos (Dissertação de Mestrado, Universidade Federal Fluminense, Niterói, Brasil).

Pollak, M. (1992). Memória e Identidade Social. Estudos Históricos, 5(10), 200-212.

Póvoa-Neto, H. (2012). Entrevista: migração: processo espontâneo é criminalizado. REVISTA IHU ON-LINE, Edição 546. Disponível em

http://www.ihu.unisinos.br/entrevistas/509050-migracao-processo-espontaneo-e -criminalizado-entrevista-especial-com-helion-povoa-neto

Rousso, H. (2006). A memória não é mais o que era. In J. Amado, \& M. de Morais Ferreira (Coords.), Usos e abusos da história oral (pp. 93-102). Rio de Janeiro: FGV.

Santos, M. S. dos (1993). O pesadelo da amnésia coletiva: um estudo sobre os conceitos de memória, tradição e traços do passado. Revista Brasileira de Ciências Sociais, $8(23), 70-85$.

Santos, M. S. dos (2017). Elos possíveis entre Facebook e memória: uma reflexão. Revista da Semana Discente de Sociologia Política do Instituto Universitário de Pesquisas do Rio de Janeiro, 1(1).

Sayad, A. (1998). Imigração ou os paradoxos da alteridade. São Paulo: Edusp.

Woischnik, J. (Ed.) (2017). Fluxos Migratórios e Refugiados na Atualidade. Rio de Janeiro: Fundação Konrad Adenauer Stiftung.

Data de submissão: 27/08/2019 | Data de aceitação: 03/11/2020 